\title{
A Study on Water Repellent Effectiveness of Natural Oil-Applied Soil as a Building Material
}

\author{
Jong-Kook Lee, Jee-Eun Lee, Seong-Cheol Park, Hee-Dong Cho, Hye-Woong Yoo, \\ Young-Sang Kim, Seong-Ryong Ryu, Woo-Suk Kim, Dong-Joon Ahn*
}

School of Architecture, Kumoh National Institute of Technology, Gumi, Republic of Korea

Email: ljk@kumoh.ac.kr, Ize@nate.com, chel2park@naver.com, lipong83@naver.com, hwyoo60@naver.com, chello8068@hanmail.net, archiryu@kumoh.ac.kr, kimw@kumoh.ac.kr, ${ }^{*}$ djahn@kumoh.ac.kr

Received 27 February 2015; accepted 17 March 2015; published 18 March 2015

Copyright (C) 2015 by authors and Scientific Research Publishing Inc.

This work is licensed under the Creative Commons Attribution International License (CC BY).

http://creativecommons.org/licenses/by/4.0/

(c) (i) Open Access

\section{Abstract}

This study was performed to investigate the water repellent effectiveness of natural oil-applied soil when it is used as a building material. Natural oil types such as olive oil, bean oil, perilla oil and linseed oil, which are being used for producing water repellent timber, are selected for the experiments. It is expected that perilla oil and in seed oil, which are drying oil types will have better water repellent effectiveness than the other types. For the evaluation of water repellence of natural oil-applied soil, a contact angle test was performed. A contact angle of water drop on various surface conditions were tested, and large differences were seen between the natural oil-applied soil and untreated soil. As a result, it is showed that all natural oil types have water repellent effectiveness. However, linseed oil, which is a drying oil type, shows an outstanding water repellent effectiveness value, while perila oil, which is also a drying oil type, shows the lowest value. Additionally, results show that there is no link between water repellent effectiveness and the number of applications of natural oil. Nevertheless, existing commercial water repellents show better performance than natural oil, and it is anticipated that the results of this study will provide essential information for further research to enhance the water repellent effectiveness of soil as a building material.

\section{Keywords}

Natural Oil, Water Repellent, Soil as a Building Material, Contact Angle, Iodine Value

\footnotetext{
${ }^{*}$ Corresponding author.
}

How to cite this paper: Lee, J.-K., Lee, J.-E., Park, S.-C., Cho, H.-D., Yoo, H.-W., Kim, Y.-S., Ryu, S.-R., Kim, W.-S. and Ahn, D.-J. (2015) A Study on Water Repellent Effectiveness of Natural Oil-Applied Soil as a Building Material. Open Journal of Civil Engineering, 5, 139-148. http://dx.doi.org/10.4236/ojce.2015.51014 


\section{Introduction}

Construction industry has been blamed for environmental pollution and massive energy consumption. Many attempts have been taken to create more eco-friendly environments and especially to make more sustainable building materials. Accordingly, an increase in research on traditional architecture has developed an interest in soil as a building material. Historically, soil has been a popular building material in Asian traditional culture. Especially in Korea, Hwangtoh ${ }^{1}$, literally meaning yellow soil in Korean, has been widely used in traditional architecture for thousands of years. Korean traditional architectures mostly are wood frame buildings, and Hwangtoh is used to build a solid wall between wood columns as an infill material (Figure 1 \& Figure 2).

Soil does not pollute the environment; on the other hand, it ensures the strength of structures and it is readily available in the vicinity. Additionally, soil is proven to have ability to control humidity by seizing moisture within it. However, soil as a building material is difficult to insulate and clad with other materials, and it loses strength when exposed to water. For these reasons, soil needs to overcome several weak points to become a typical building material for modern architecture. In this study, a variety of experiments, which are used to enhance water repellent capacity of timber, will be conducted on soil, and the results will show the best practical method to improve water repellent effectiveness of soil as a building material.

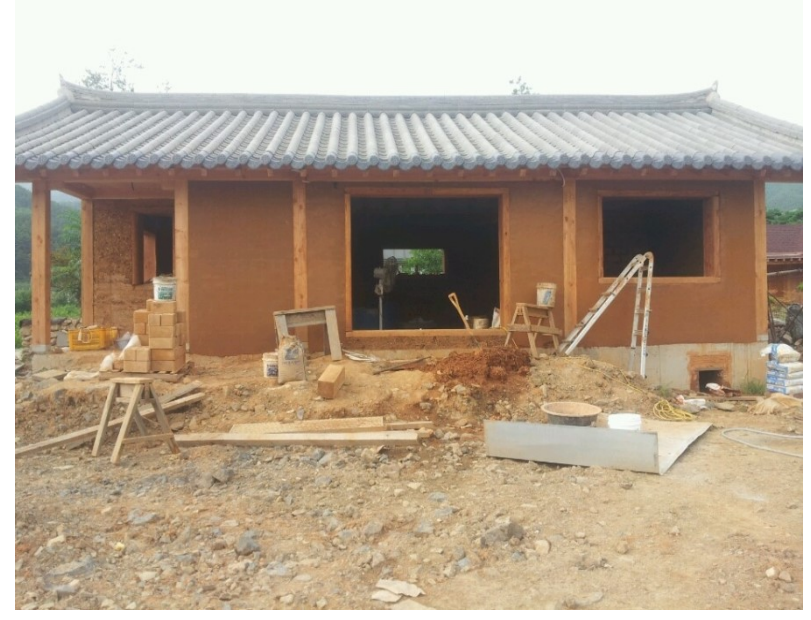

Figure 1. A Korean traditional architecture.

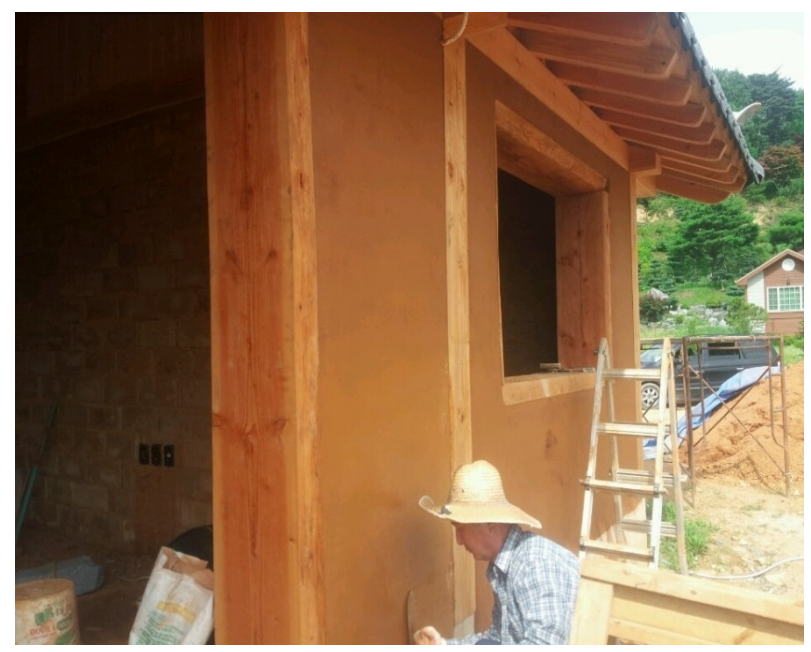

Figure 2. Hwangto wall construction.

\footnotetext{
"'Hwangtoh”, a Korean name of yellow soil, created by weathering process of local bedrocks in Korea, and different from Loess which is found in Hwang river area in China and other areas in Europe and North America [1].
} 


\section{Methods of Study}

\subsection{Water Repellents}

The definition of water repellents is first to be clarified. When applied in liquid state to a building material, water repellents are absorbed by the surface material and they indurate within pore spaces. Hardened water repellents then push water out by creating high contact angle between water particle and the surface material. Unlike water proofing materials, water repellents become a barrier of moisture in outside air and rainwater, but internal moisture can still be evaporated and removed to outside. Additionally water repellents become effective in the area only where it is exposed to air, and this explains that air plays a role in the hardening process of water repellent. Generally, water proofing materials block incoming water completely from outside, but moisture produced from inside can be trapped and cause condensation, mildew and damage to structural elements. However, water repellents do not block a capillary action completely, so a certain amount of moisture can travel inside and outside. Therefore, water repellents are commonly used in many architectural applications except roofing where water proofing is required. Water repellents can control the pace of water penetration by block pore spaces within building materials, but apparently they are not the suitable material to block a large gap of space [2].

Secondly, how water repellents push water out needs to be examined. In this study, contact angle test [3] is used to evaluate effectiveness of water repellents. Contact angle is the angle that is made by the tangent of the edge of a water drop with the surface (Figure 3). Typically, a material with higher surface tension is measured to have higher contact angle, and water drops fall off the surface quickly when contact angle is higher than $90^{\circ}$. When contact angle is higher than $90^{\circ}$, then the surface is called water repellent [4]. Therefore, characteristics of material in terms of contact angle are the key factor to evaluate effectiveness of water repellents.

A considerable amount of researches support the methods of this study. Utilizing bean water as water repellents on soil was introduced (Hwang, 2008), and a variety of mixing ratio between bean and water were tested. As an alternative of bean water, natural oil such as perilla oil and linseed oil has been tested to find out appropriate mixing ratio for water repellents [2]. Traditionally, natural oil has been used for water repellants of architectural timber (Lee, 2002) [5], and other studies show that most of natural oil types have water repellent effectiveness on timber and other building materials such as paper based product (Jang, 2009) [6].

\subsection{Natural Oil Types}

Based on the results from other researches mentioned above, this study takes the characteristics of natural oil to soil, and provides essential data for eco-friendly water repellents which can be applied to soil. Natural oil types are classified according to the iodine value. The iodine value is the mass of iodine in grams that is consumed by 100 grams of a chemical substance, and it indicates the amount of unsaturated fatty acids. According to this value, dryness of natural oil can be predicted and classified into 3 groups as shown below (Table 1): 1) Perilla oil and linseed oil had iodine value of 130 and higher. These types are drying oils which turn into a solid film when exposed to the air. 2) Bean oil had an iodine value of between 100 and 130. This type is semi-drying oil which partially hardens when exposed to air. 3) Olive oil had an iodine value of 100 and lower. This type is a non-drying oil which does not harden at all when exposed to the air. In this study, perilla oil and linseed oil as drying oil types, bean oil as a semi-drying oil type, and olive oil as a non-drying oil type were selected for the test, respectively.

\subsection{Specimens}

Specimens of soil are selected from 100\% Hwangtoh bricks which are processed with high pressure injection method by "A" company. Characteristics of specimens are shown as below (Table 2 \& Figure 4). They are fa-

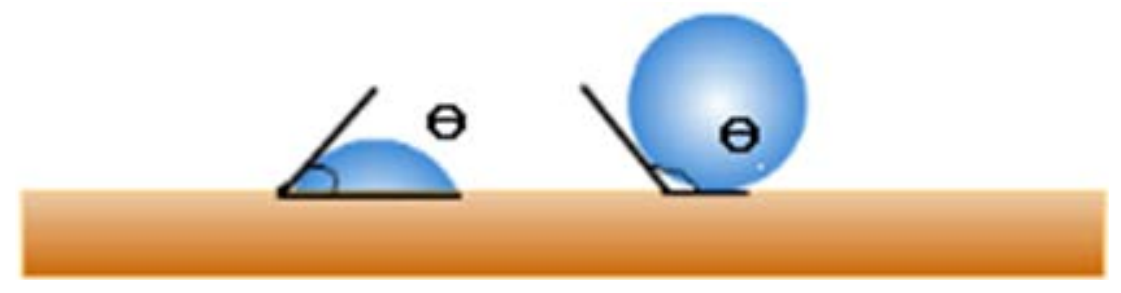

Figure 3. A water drop on a surface and the contact angle. 
Table 1. Examples of natural oil types and selected oils for the test.

\begin{tabular}{|c|c|c|c|c|c|}
\hline Category & Iodine value & Example & Selected oil & Iodine value & Manufacturer \\
\hline Non-drying oil & Under 100 & $\begin{array}{c}\text { Camellia oil, castor oil, } \\
\text { olive oil }\end{array}$ & Olive oil & 85 & “A” company \\
\hline Semi-drying oil & $100-130$ & $\begin{array}{l}\text { Corn oil, cottonseed } \\
\text { oil, bean oil, sesame } \\
\text { oil }\end{array}$ & Bean oil & 125 & "B" company \\
\hline \multirow{2}{*}{ Drying oil } & \multirow{2}{*}{ Over 130} & \multirow{2}{*}{$\begin{array}{l}\text { Linseed oil, tung oil, } \\
\text { perilla oil }\end{array}$} & Perilla oil & 198 & "B" company \\
\hline & & & Linseed oil & 190 & "B" company \\
\hline
\end{tabular}

Table 2. Characteristics of a specimen.

\begin{tabular}{cc}
\hline Compressive strength & Porosity \\
\hline $3.41 \mathrm{~N} / \mathrm{mm}^{2}$ & $35 \%-45 \%$ \\
\hline
\end{tabular}

bricated into standard size for experiments, $50 \mathrm{~mm}$ in width and length, and $8 \mathrm{~mm}$ in height. The surface of specimens is maintained clean by grinding with sandpapers.

\subsection{Process of Experiments}

In the experiment, natural oils were classified into 3 types: drying oil, semi-drying oil, non-drying oil. Two specimens for drying oil types and one specimen per other oil types are to be tested. Additionally, two specimens for comparison were set up, one for commercial water repellents and the other for an untreated. All natural oils are applied by a brush and specimens were categorized by the number of applications: 1,2 , and 3 times (Table 3 \& Figure 5). Before tests, natural oils and commercial water repellents need to be completely dry in order to perform as water repellents. After each application, specimens were maintained in shaded room for 3 days at $25^{\circ} \mathrm{C}$ and $60 \%$ humidity, so all specimens are under the same condition for tests.

\subsection{Contact Angle Test}

Prepared specimens were tested with SEO-300A Contact Angle analyzer (Figure 6) to capture the moment when water was dropped on the surface by a pipette, and measurements and analysis were conducted with SEO software. During the tests, the lab was maintained at $20^{\circ} \mathrm{C}$ and $60 \%$ humidity.

\section{Results and Analysis}

\subsection{Results of the Test}

1) Untreated specimen

In the test of untreated specimen, water was absorbed as soon as it hits the surface, and no water drop was left. Therefore, measuring a contact angle of water drop was not possible (Table 4).

2) Specimens with non-drying oil types

In case of olive oil as non-drying oil types, the contact angle rises as number of application times increases, and average of contact angle from 1, 2 and 3 times application was 62.88 (Table 5). The contact angle of 3 times application was slightly higher than 2 times, however, the difference of contact angle between 2 and 3 times applications was insignificant, $0.85^{\circ}$, as shown in the chart below (Figure 7).

3) Specimens with semi-drying oil types

In case of bean oil as semi-drying oil types, the contact angle of 2 and 3 time applications were higher than 1 time application, and average of contact angle from 1, 2 and 3 times application was 62.94 (Table 6). However, the results show that contact angle of 3 times application was lower than 2 times, and the difference was $4.22^{\circ}$ as shown in the chart below (Figure 8).

4) Specimens with drying oil types

In the test of specimens with drying oil types, both perilla oil and linseed oil were used. In overall comparison of the two oil types, the average contact angle from 1, 2 and 3 times application of perilla oil was $56.13^{\circ}$ and linseed oil was $81.10^{\circ}$ (Table $7 \&$ Table 8 ). In the case of perilla oil, the contact angle of 1 time application was 
Table 3. Experimental classification and number of applications.

\begin{tabular}{|c|c|c|c|}
\hline \multicolumn{3}{|c|}{ Experimental classification/Oil types } & \multirow{2}{*}{$\begin{array}{c}\text { Number of applications } \\
0\end{array}$} \\
\hline \multirow{6}{*}{ Natural oil } & Untreated & & \\
\hline & Non-drying oil & Olive oil & $1-3$ times \\
\hline & Semi-drying oil & Bean oil & 1 - 3 times \\
\hline & \multirow{2}{*}{ Drying oil } & Linseed oil & 1 - 3 times \\
\hline & & Perilla oil & 1 - 3 times \\
\hline & Commercial water repe & & $1-3$ times \\
\hline
\end{tabular}

Table 4. Untreated specimen.

\begin{tabular}{lll}
\hline Average contact angle & Photography \\
\hline & \\
\hline
\end{tabular}

Table 5. Non-drying oil type specimen-Oilve oil.

Average contact angle

Table 6. Semi-drying oil typespecimen-Bean oil.

Average contact angle

Table 7. Drying oiltype specimen-Perilla oil.

Average contact angle


Table 8. Drying oil type specimen-Linseed oil.

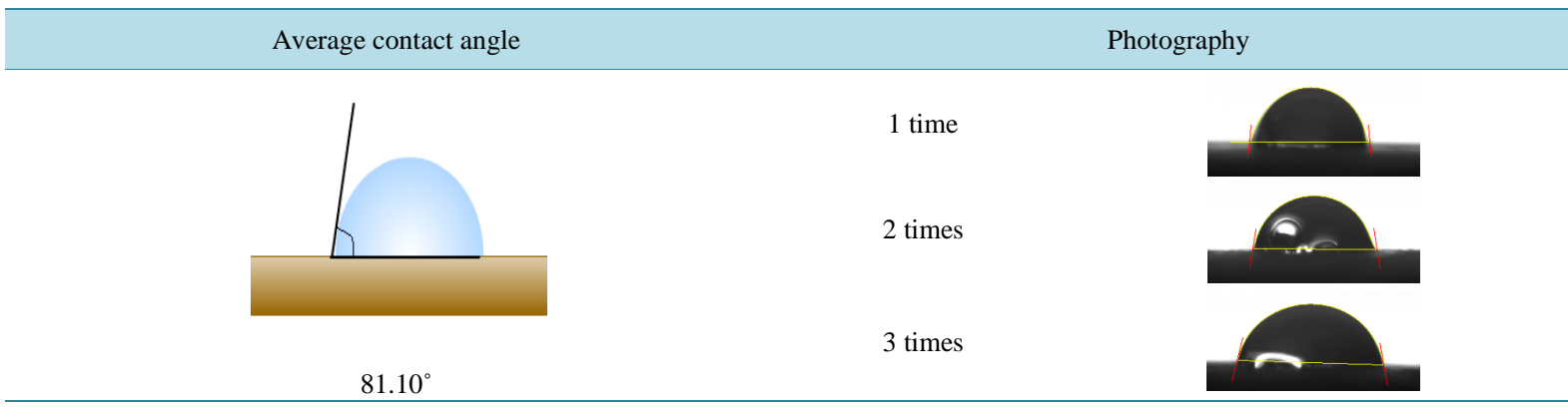
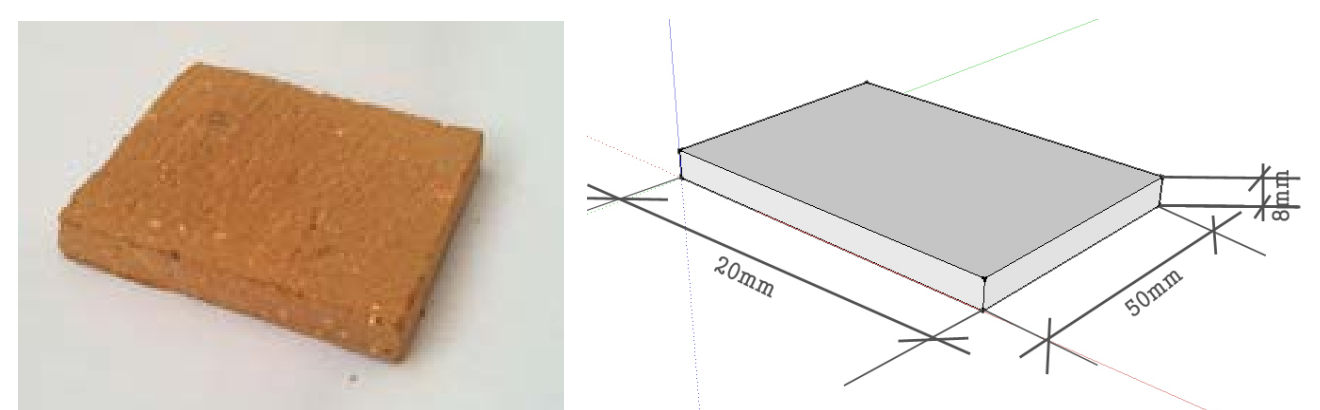

Figure 4. Specifications of a manufactured specimen.

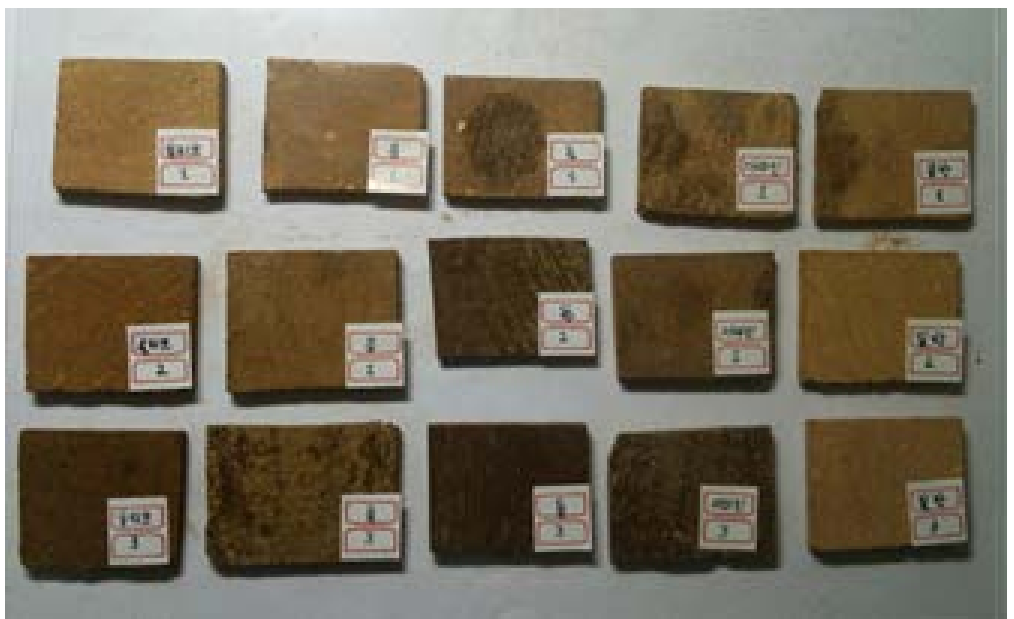

Figure 5. Classified specimens for the experiment.

the highest, $62.09^{\circ}$, and 2 times was dropped to $52.04^{\circ}$, and 3 times was increased again to $53.86^{\circ}$. In the case of linseed oil, the results shows the highest average value of contact angle among all natural oil types, however the contact angle of 1 time application, $84.4^{\circ}$, was decreased with the range of $3.2^{\circ}$ to $3.3^{\circ}$ increment, as the more application of oil was provided (Figure 9).

5) Specimens with commercial water repellents

In the case of specimens with commercial water repellents, the contact angle of all three applications was higher than $100^{\circ}$, and the average was $130.65^{\circ}$ (Table 9). The contact angle of 1 time application was the highest, $142.28^{\circ}$ and 2 times was dropped to $115.15^{\circ}$, and 3 times was increased again to $134.51^{\circ}$ as shown in the chart below (Figure 10).

\subsection{Analysis of the Test Results}

1) Comparison of contact angle by iodine value 


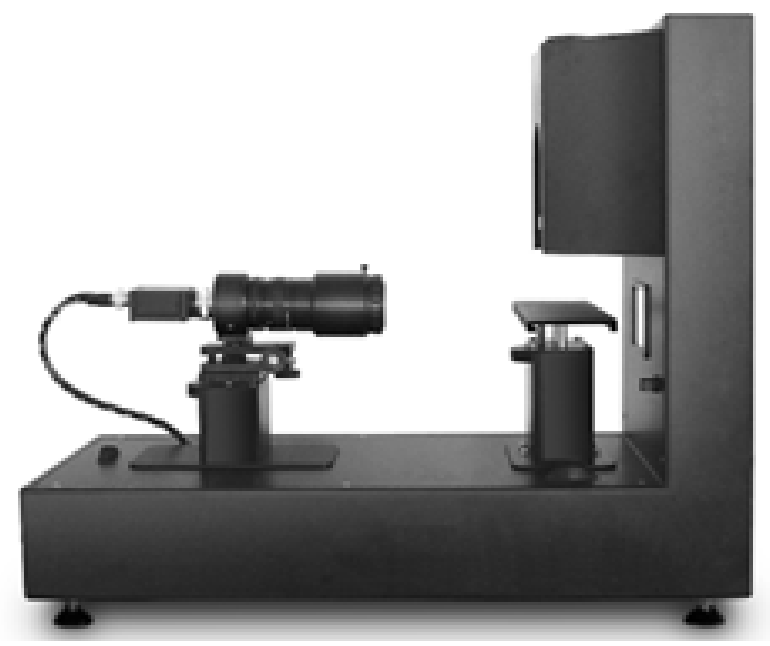

Figure 6. Contact angle anglyzer (SEO-300).



Figure 7. Non-drying oil type fluctuation chart-Olive oil.

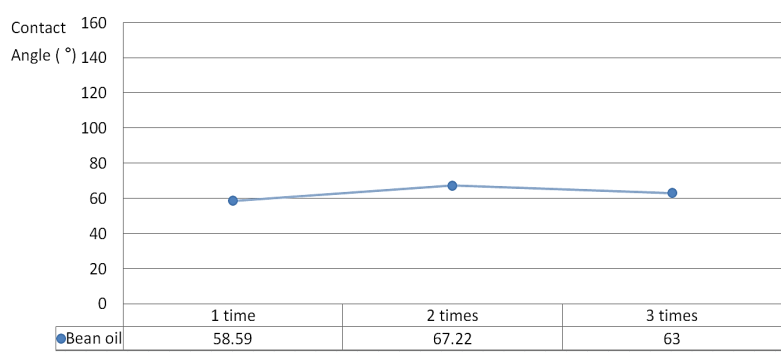

Figure 8. Semi-drying oil type fluctuation chart-Bean oil.

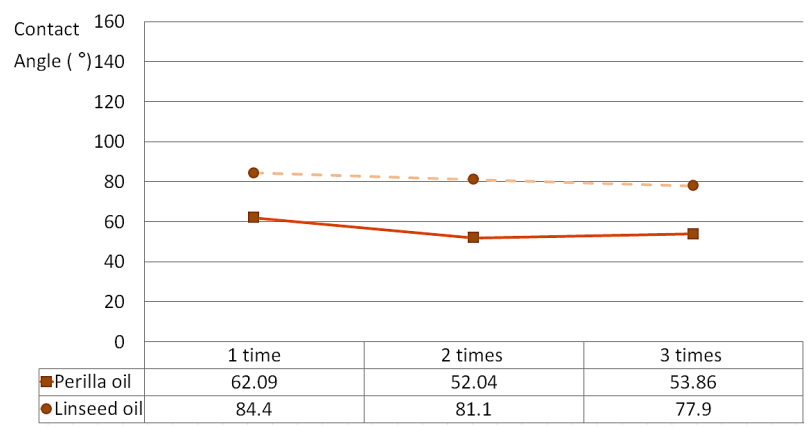

Figure 9. Drying oil type fluctuation chart-Perilla oil and linseed oil.

The contact angle test results from 4 different natural oil types are shown with iodine value in the chart below (Figure 11). Perilla oil and linseed oil are both classified as drying oil and have iodine value of 198 and 190 re- 


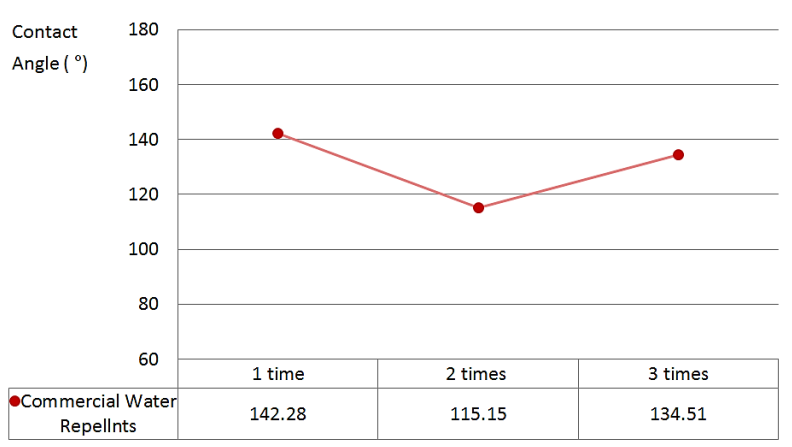

Figure 10. Commercial water repellents fluctuation chart.

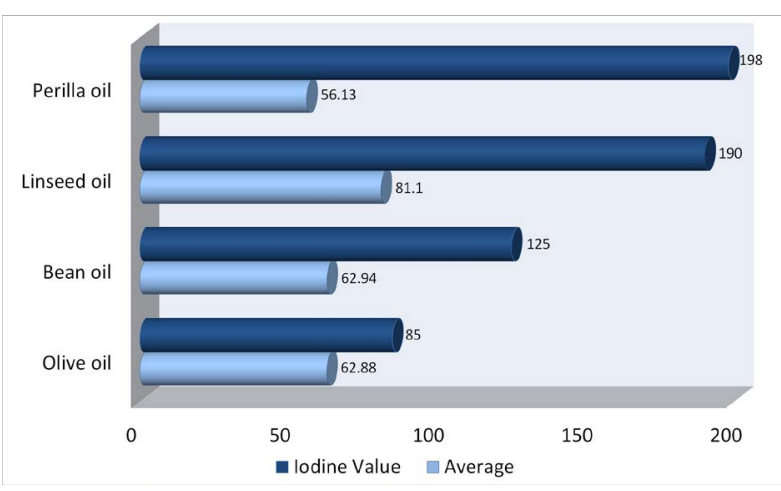

Figure 11. A comparison chart of contact angle and iodine value of 4 different natural oil types.

Table 9. Commercial water repellents specimen.

Average contact angle

spectively, which are higher than semi-drying and non-drying oil types. However, the contact angle of perilla oil shows $56.13^{\circ}$, the lowest among 4 natural oil types, and the contact angle of linseed oil shows $81.1^{\circ}$, the highest. And the test results of bean and olive oil, which have iodine value of 125 and 85 respectively, show higher contact angle than perilla oil which has iodine value of 198. Additionally, difference of iodine value between bean oil and olive oil did not result any significant difference in contact angle, although their iodine values are quite different. Therefore, it can be seen that contact angle of natural oil is not determined in accordance with the iodine value.

2) Comparison of contact angle by number of applications

The contact angle test results from 6 specimens, untreated, olive oil, bean oil, perilla oil, linseed oil and commercial water repellants are shown by number of application in the chart below (Figure 12). In the results, it is found that contact angle does not increase in exact proportion to the number of applications, and none of specimens showed linear rising curves in fluctuation chart of contact angle as the more application of oil was provided (Figures 7-10). In the cases of perilla and linseed oil, the results showed that contact angle of 2 and 3 


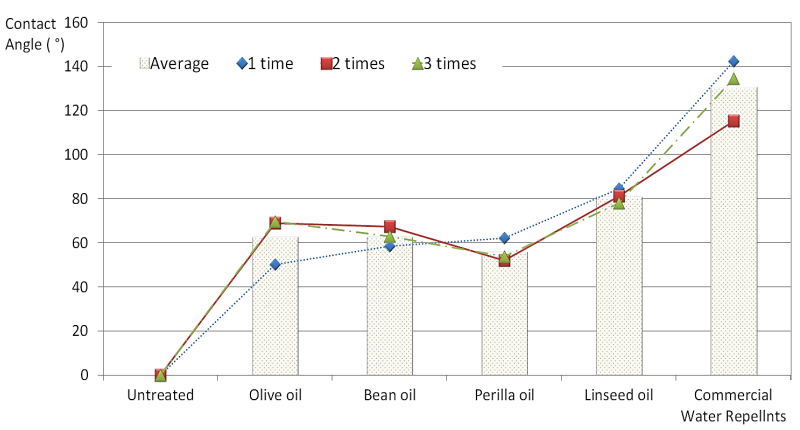

Figure 12. A comparison chart of contact angles by number of applications.

times of application were decreased from 1 layer, and the difference between 2 and 3 times of application was not significant. Therefore it can be seen that 2 and 3 times of application in drying oil types do not improve water repellent effectiveness of soil. In the case of olive and bean oil, contact angle of 2 and 3 times of application was increased from 1 time. However, in olive oil's case, the amount of increase from 2 times to 3 times was only $0.85^{\circ}$, and in bean oil's case, contact angle of 3 times of application was less than 2 times. Therefore it can be seen that additional applications after 2 times in olive and bean oil do not improve water repellent effectiveness of soil.

\section{Conclusions}

Soil as a new building material is considered as an eco-friendly alternative, but has a disadvantage of dissolving in water. As a supplement of this water issue of soil, water repellent performances of natural oils, which previously used in timber construction, was tested on the surface of soil in order to evaluate effectiveness as water repellents. The selected natural oil types are all available on the market and classified according to the iodine value. With the comparison of specimens among untreated, natural oil types and commercial water repellents, this study results in the conclusions below.

1) Upon completion of the contact angle tests, significant differences were seen between the natural oil treated specimens and an untreated specimen. Although the contact angle of all natural oil treated specimens showed less than $90^{\circ}$, they are increased significantly compared to an untreated specimen. Therefore, it can be seen that all natural oil types have potential water repellent effectiveness in some degrees.

2) Natural oil types were classified according to the iodine value, and the results of the contact angle tests were compared with those of other oil types. Linseed oil, which is a drying oil type, returned an outstanding water repellent effectiveness value, while perilla oil, which is also a drying oil type, showed the lowest value. Therefore, water repellent effectiveness of natural oil is not determined in accordance with oil types classified by the iodine value.

3) The comparison of contact angle by the number of applications shows that there is no directrelation between water repellent effectiveness and number of applications. Only in the case of olive oil, contact angle of 2 layers was increased noticeably from 1 layer, but in all other cases, the fluctuation of contact angle was insignificant or even decreased as the number of application grows. Therefore, the number of water repellent applications is not expected to improve water repellent effectiveness.

3 major statements above has been made based on the test results of contact angle and water repellent effectiveness, however, the results of this study need to be further observed in terms of durability and longevity of water repellent effectiveness. Additionally, this study was focused on water repellent effectiveness, but overall water resistance performance of building materials is based on balanced integration of water repellence, moisture permeability and water proofing. Therefore, more research about other variables mentioned above and interrelation between them need to be followed in the future in order to make this study more meaningful.

\section{Acknowledgements}

This research was supported by Research Fund, Kumoh National Institute of Technology (2013-104-049). 


\section{References}

[1] Hwang, H.Z. (2008) Earth Architecture. CIR Publishing, Seoul.

[2] Hwang, H.Z., Kang, N.Y. and Seo, E.H. (2008) A Study on the Development of Nature-Friendly Water Repellents Using Traditional Finishing Techniques. Journal of Architectural Institute of Korea (Structure), 24, 43-50.

[3] American Society for Testing and Materials (ASTM) D7490:13.

[4] Minke, G. (2000) Earth Construction Handbook. WIT Press, Southampton.

[5] Lee, D.H. (2002) The Evaluation of Water Repellent Effectiveness of Natural Oil Treated Wood. Journal of the Korea Forest BioEnergy Research Society, 21, 34-42.

[6] Jang, M.H. (2009) A Study on the Wall Finishing Process with Han-Ji, an Eco-Friendly Material. Journal of the Korea Institute of Ecological Architecture and Environment, 9, 29-36 